\title{
Clinical and Biochemical Characteristics of Autoantibody Systems in Polymyositis and Dermatomyositis
}

\author{
By Edward J. Fudman and Thomas J. Schnitzer
}

$\mathbf{P}$ OLYMYOSITIS (PM) and dermatomyositis $(D M)$ are inflammatory muscle diseases of unknown etiology. There is strong evidence for cellular immune mechanisms of muscle damage in these disorders. In recent years, numerous autoantibodies have been identified in patients with myositis, but their role in producing this clinical syndrome is unknown. In this report, we summarize the current state of knowledge about myositis-related autoantibodies, including characterization of the antigens, epidemiology, clinical significance, and the clues these autoantibodies may provide concerning the etiology and pathogenesis of the disease.

\section{ANTIBODIES TO MUSCLE PROTEINS}

The search for autoantibodies in patients with PM started with attempts to detect antibodies against muscle fibers and individual muscle proteins. The initial studies, using indirect immunofluorescence with muscle as the substrate, found no differences among sera of patients with PM, other muscle diseases, and normals. ${ }^{1}$ This may have been a consequence of the strong nonspecific affinity of immunoglobulins for skeletal muscle fibers.

Further investigations of antibodies to specific muscle components, particularly human myosin and myoglobin, have detected such antibodies in sera of patients with PM. Depending on the assay used, there is varying specificity for the disease. Antibodies to myosin were initially reported to be present in almost $50 \%$ of sera from patients with PM, but were also present in a similar percentage of sera from patients with other neuromuscular diseases and healthy controls. ${ }^{2}$ Using more highly purified myosin, Wada et al have recently developed a radioimmunoassay for antibodies to myosin and have found such antibodies in 18 of 20 patients $(90 \%)$ with PM. A high degree of specificity for this assay was claimed as antibodies were present in only six of 33 patients (18\%) with other muscle diseases, and then in much lower titer. Antibodies to myosin were not detected in 43 patients with other neurologic or autoimmune diseases. ${ }^{3}$

Antibodies to myoglobin were reported by
Nishikai and Homma to be present in seven of eleven patients with PM using a double immunodiffusion assay. None was detected in a total of 64 patients with rheumatoid arthritis (RA), systemic lupus erythematosus (SLE), scleroderma, and in normals. However, patients with other myopathies were not studied as controls. ${ }^{4}$ In a subsequent study, the investigators used a passive hemagglutination technique and detected antibodies to myoglobin in $71 \%$ of patients with PM. The antibody was not specific for PM as antibodies to myoglobin were also detected in patients with myasthenia gravis $(31 \%)$, muscular dystrophy $(10 \%)$, and in low titer in some patients with RA, SLE, and scleroderma. ${ }^{5}$

Antibodies to muscle proteins such as myosin and myoglobin are probably nonspecific reactions to muscle injury and subsequent release of these antigens. It is difficult to understand how antibodies to such internal muscle proteins could play a role in the initiation of muscle damage. The assays described above are not generally used for the diagnosis or observation of patients with PM.

\section{ANTIBODIES TO NUCLEAR AND CYTOPLASMIC ANTIGENS}

In recent years, the focus of study of autoantibodies in PM has shifted from muscle to subcellular particles. Some of the autoantibodies are detected by immunofluorescence testing and the

From the Division of Rheumatology, Department of Internal Medicine, University of Michigan Medical Center, Ann Arbor, Mich; and the Section of Rheumatology, Department of Internal Medicine, Rush-Presbyterian-St Luke's Medical Center, Chicago.

Edward J. Fudman, MD: Fellow in Rheumatology, Division of Rheumatology, Department of Internal Medicine. University of Michigan Medical Center, Ann Arbor. Mich; Thomas J. Schnitzer, MD, PhD: Professor and Chief, Section of Rheumatology, Department of Internal Medicine. Rush-Presbyterian-St Luke's Medical Center, Chicago.

Address reprint requests to Thomas J. Schnitzer, MD, PhD, Section of Rheumatology, Room 297 Jelke, RushPresbyterian-St Luke's Medical Center, $1753 \mathrm{~W}$ Congres. Pkwy, Chicago, IL 60612.

(1) 1986 by Grune \& Stratton, Inc:

$0049-0172 / 86 / 1504-0002 \$ 5.00 / 0$ 
Table 1. Biochemical Characteristics of Antigens Recognized by Myositis-Related Autoantibodies

\begin{tabular}{|c|c|c|c|c|}
\hline Antigen & Location & Predominant ANA Pattern & Properties or Function & References \\
\hline Ku & Nucleus & Reticular nuclear* & Protein, binds free ends of dsDNA & 6.7 \\
\hline Jo-1 & Cytoplasm & Variable & Histidyl tRNA synthetase & 30,31 \\
\hline $\mathrm{Mi}-1$ & Nucleus & $\begin{array}{l}\text { Weak rimt } \\
\text { Particulate } \neq\end{array}$ & $\begin{array}{l}\text { Protein, shares antigenic determinants with } \\
\text { bovine lgG }\end{array}$ & 10 \\
\hline Mi-2 & Nucleus & Homogeneous & Protein, unknown function & 11 \\
\hline $\mathrm{Pm}-\mathrm{Scl}$ & Nucleolus & Nucleolar & Protein, unknown function & $12-15$ \\
\hline nRNP & Nucleus & Speckled & Ribonucleoprotein containing U 1 RNA & 16 \\
\hline
\end{tabular}

* On human liver substrate; negative on rat liver substrate.

†On mouse liver substrate.

‡On mouse spleen substrate.

remainder are identified as precipitin lines in double immunodiffusion assays against specified tissue extracts (Tables 1 and 2).

The introduction of human epithelial cells as a substrate for antinuclear antibody (ANA) assays has greatly enhanced the usefulness of this procedure to detect autoantibodies in PM. When rodent liver or kidney was used as the tissue substrate for indirect immunofluorescence, antinuclear antibodies were detected in about one third of patients with PM. ${ }^{25,26}$ However, using HEp-2 cells (a human-derived cell line) as the substrate, 89 of $114(78 \%)$ sera from patients with PM were positive. Both nuclear and cytoplasmic staining were observed. The most common pattern was fine speckled staining of the nucleus $(61 \%)$, followed by homogeneous cytoplasmic staining (19\%), and a nucleolar pattern (10\%). Other patterns identified were centromere, small bright speckled, nuclear and cytoplasmic, nucleolar and centromere, and filamentous cytoplasmic. No single pattern on HEp-2 cells predominated among the sera that were negative on mouse kidney substrate. ${ }^{25}$ There are no known correlations between the pattern of HEp-2 staining and the clinical syndrome.

Using a complement fixation assay, Reichlin and Mattioli in 1976 first detected an antibody to calf-thymus extract in the serum of a patient with DM. ${ }^{27}$ Subsequent study of this prototype serum, $\mathrm{Mi}$, using agar gel diffusion found at least two different precipitating antigens. One, designated Mi-1, was a protein with a molecular weight (mol wt) of 150,000 daltons that appeared to bear some antigenic relationship to bovine IgG although it was not an immunoglobulin. Antibodies to Mi-1 were detected in two of 19 patients with DM but in 0 of 39 patients with PM, 60 patients with other connective tissuc or muscle diseases, or 18 healthy controls. Later studies of anti-Mi-1 found this antibody to be present in about $5 \%$ of sera from patients with SLE. These sera also contained other precipitating antibodies, predominantly $\mathrm{Sm}$ or nRNP. Anti-Mi-1 was not found in sera from patients with SLE which did not also contain other precipitating antibodies..$^{24}$ Anti-Mi-1 sera produced varying ANA patterns depending on the substrate used. ${ }^{10}$

The second antibody in Mi serum, Mi-2, is the complement fixing antibody originally described by Reichlin and Mattioli. Of the known autoantibodies, anti-Mi-2 is the most specific for DM, present by ELISA in 11 of 52 patients with DM,

Table 2. Clinical Characteristics of Myositis-Related Autoantibodies

\begin{tabular}{|c|c|c|c|}
\hline Autoantibady & Prevalence in Myositis & Other Disease Associations & References \\
\hline $\mathrm{Ku}$ & $\begin{array}{l}50 \% \text { of PM-scleroderma overlap in Japa- } \\
\text { nese patients }\end{array}$ & $\begin{array}{l}\text { Present in } 5 \% \text { of American patients with } \\
\text { SLE }\end{array}$ & $6,7,17$ \\
\hline Jo- 1 & $\begin{array}{l}30 \% \text { of } \mathrm{PM},<10 \% \text { of } \mathrm{DM}, 50 \% \text { to } \\
100 \% \text { of } \mathrm{PM} \text { with interstitial lung dis- } \\
\text { ease }\end{array}$ & $\begin{array}{l}\text { Rarely detected in interstitial lung disease } \\
\text { without myositis }\end{array}$ & $\begin{array}{c}8,18 \\
21-23 \\
29\end{array}$ \\
\hline $\mathrm{Mi}-1$ & $3 \%$ of $\mathrm{DM}$, not detected in $\mathrm{PM}$ & Present in $5 \%$ of SLE & 10,24 \\
\hline $\mathrm{Mi}-2$ & $20 \%$ of $\mathrm{DM}$, rare in $\mathrm{PM}$ & None known & 11 \\
\hline $\mathrm{Pm}-\mathrm{Scl}$ & $\begin{array}{l}8 \% \text { of PM (half have PM-scleroderma } \\
\text { overlap) }\end{array}$ & $\begin{array}{l}\text { Rarely detected in scleroderma without } \\
\text { myositis }\end{array}$ & $12-14,25$ \\
\hline nRNP & $4 \%$ to $15 \%$ of $P M$ and $D M$ & Common in SLE and overlap syndromes & 18,25 \\
\hline
\end{tabular}


but in only two of 87 patients with PM. None of 93 patients with other connective tissue diseases or 35 healthy controls had significant titers of anti-Mi-2. ELISA proved to be more sensitive than immunodiffusion as immunodiffusion detected anti-Mi-2 only in patients with DM, and only in those patients with a strongly positive ELISA for Mi-2 antibodies. Studies using partially purified $\mathrm{Mi}-2$ antigen showed it to be protein with major bands of 53,000 and 61,000 daltons by SDS-polyacrylamide gel electrophoresis. Anti-Mi-2 sera yields a homogeneous nuclear ANA pattern with either HEp-2 or mouse liver substrate. ${ }^{11}$

Antibodies to a different cellular antigen were identified in 1977 by Wolfe et al, who noted a line of precipitation in double immunodiffusion between calf thymus nuclear extract and sera of patients with myositis. ${ }^{12}$ This antigen-antibody system, originally designated PM-1, was subsequently found to give multiple lines of precipitation. The predominant antigen has been named PM-Scl. Fifty percent to $66 \%$ of the patients with antibody to PM-Scl have an overlap syndrome of scleroderma and myositis; the remainder have only PM or DM. The antibody has also been rarely found in patients with scleroderma without myositis. ${ }^{13,14}$ Antibodies to PM-Scl were identified in $8 \%$ of 168 myositis patients. ${ }^{25}$ Longitudinal studies have shown that antibody status at time of diagnosis remains constant and does not change with disease activity. ${ }^{12}$

Attempts to characterizc the PM-Scl antigen have shown it to be primarily nucleolar in location when examined by immunofluorescent techniques. ${ }^{13}$ Further evidence for the nucleolar origin of PM-Scl is provided by a study that showed nucleolar extracts to be 10 - to 50 -fold enriched for PM-Scl antigen over whole calf thymus extract, whereas nucleoli-poor fractions did not demonstrate the antigen. ${ }^{15}$ The PM-Scl antigen has been shown to be a heat sensitive, trypsin sensitive acidic protein and to be DNAse and RNAse resistant. It has not been completely purified and its function remains unknown. ${ }^{12,14}$

A second autoantibody found in patients with PM-scleroderma overlap is anti-Ku. Antibodies to $\mathrm{Ku}$ were originally described in nine of a series of 330 Japanese patients with connective tissue disease. Seven had a PM overlap syndrome (six PM-PSS, one PM-PSS-SLE), one had PSS, and one had SLE. Three of the nine patients also had anti-PM-Scl antibodies. ${ }^{6}$ Anti-Ku has also been found in American patients, present in three of 60 with SLE. ${ }^{17}$ Biochemical studies have shown $\mathrm{Ku}$ to be a protein that binds specifically to the free ends of double-stranded DNA. ${ }^{7}$ By indirect immunofluorescent technqiues, the antigen has been localized to the nucleus but spares the nucleolus. ${ }^{6}$

At this time, antibodies to $\mathrm{Mi}-1, \mathrm{Mi}-2, \mathrm{PM}$ $\mathrm{Scl}$, and $\mathrm{Ku}$ are all laboratory findings without any known or hypothesized relationship to the etiology or pathogenesis of myositis. The low frequency of these autoantibodies in patients with PM and DM makes it unlikely that they play a significant role in the disease process, though their function in any individual patient is unknown. Further understanding of the significance of these autoantibodies may not be achieved until the target antigens are identified.

In distinction to these autoantibodies, another class that has been extensively investigated are those directed against nRNP. Such antibodies are usually associated with connective tissue diseases other than pure PM, including various overlap syndromes with features of SLE, scleroderma, and myositis. However, anti-nRNP has also been found in $4 \%$ to $15 \%$ of sera from patients with isolated PM and DM. ${ }^{18,25}$ Antibodies to nRNP have been shown to react with the protein components of ribonucleoproteins containing U1 RNA. ${ }^{16}$ Ribonucleoproteins containing U1 RNA appear to regulate the posttranscriptional processing of messenger RNA by ensuring the precise excision of unneeded segments from newly transcribed hetereogeneous nuclear RNA. ${ }^{28}$ Anti-RNP antibodies have been shown to block this processing activity in cell free systems. ${ }^{19}$ However, a relationship between the cellular defect and the clinical syndromes in which antibodies to nRNP are found has not yet been established. A different antibody which reacts with ribonucleoproteins of U2 RNA has recently been described in one patient with PMscleroderma overlap. ${ }^{20}$ The function of this ribonucleoprotein is currently unknown.

Antibody to Jo-1 was the first autoantibody identified with reactivity against a specific enzyme. Using double immunodiffusion with calf thymus extract, Nishikai and Reichlin demonstrated a strong precipitin line of common speci- 
ficity in eight of 26 sera ( $30 \%$ ) from patients with $\mathrm{PM}$ and in one of 22 sera (4\%) from patients with DM. Of 102 patients with other connective tissue and muscle diseases, only one, a patient with PM-PSS overlap, had antibodies to Jo-1. The other ten patients with PM-PSS overlap were negative. ${ }^{21}$ Subsequent studies have confirmed the prevalence of anti-Jo- 1 in patients with PM and DM as $30 \%$ and $\angle 10 \%$, respectively, and the absence of anti-Jo- 1 in patients with other connective tissue diseases. ${ }^{18,22}$ In addition to this relationship with the clinical presentation, the production of antibody to Jo-1 may be under genetic influence. Arnett et al reported HLADR3 present in seven of 11 patients with $P M$ who were anti--Jo-1 positive (64\%) but present in only eight of 36 patients with PM who were anti-Jo-1 negative $(22 \%)$. No significant difference was found in the prevalence of HLA-DR w6 between these two groups, but all patients with Jo-1 antibodies had DR3, DRw6, or both. ${ }^{18}$

Examination of the clinical significance of antibody to Jo- 1 has shown a strong association between the presence of this antibody and interstitial lung disease. This association was initially recognized by Yoshida et al, who reported finding antibodies to Jo-1 in 11 of 324 Japanese patients with connective tissue disease. Ten of the patients had PM (including two with overlap syndromes) and one had DM. All 11 patients had interstitial lung disease by chest $x$-ray. In contrast, interstitial lung disease was present in only $22 \%$ of the patients with PM or DM who had no detectable antibody to Jo-1. There was no relationship between the titer of antibody to Jo- 1 and the severity of the interstitial lung disease, assessed either by chest $\mathrm{x}$-ray or diffusion capacity. The presence of interstitial lung disease was the only difference detected between patients positive and those negative for antibody to Jo-1. There were no significant differences between these groups in age at diagnosis, sex, creatine kinase elevation, or response to corticosteroids. ${ }^{22}$ In other studies, Bernstein et al reported finding 20 English patients with antibodies to Jo- 1 after screening 1,000 sera. Thirteen of the patients had PM with interstitial lung disease. In two of the patients with PM, antibody to Jo-1 was present when the patients had lung disease alone, before myositis was diagnosed. Of the 20 patients, two had interstitial lung disease and sclerodactyly in the absence of myositis. ${ }^{23}$ This association between antibody to $\mathrm{JO}_{\mathrm{O}}-1$ and $\mathrm{PM}$ with interstitial lung disease had also been confirmed in American patients. ${ }^{29}$ After the association was identified, it was reported that the American patient who provided the prototype serum did have PM with interstitial lung disease. $^{8}$

Attempts to localize the Jo- 1 antigen within the cell have failed to produce consistent results. About $33 \%$ of sera containing antibody to Jo- 1 are ANA-positive using mouse kidney substrate, a prevalence similar to that found in sera from patients with PM lacking antibody to Jo-1. However, using HEp- 2 cells as substrate, up to $66 \%$ of the sera with antibody to Jo- 1 could be shown to have ANA activity. Staining was predominantly nuclear, although cytoplasmic and nucleolar patterns were also seen. ${ }^{25}$ The reason for the nuclear localization is unknown as Jo- 1 is believed to be a cytoplasmic enzyme. However, a preliminary investigation showed that antibody partially purified from two sera originally demonstrating nuclcar fluorescence did give cytoplasmic fluorescence. The suggestion has been made that there may be a factor in whole serum that interferes with detection of Jo- 1 antigen by indirect immunofluoresence. ${ }^{9}$

Extensive biochemical characterization of the Jo-1 antigen has been accomplished, yielding interesting and provocative results. Initial investigations identified both protein and transfer RNA (tRNA) in the immunoprecipitate formed between HeLa cell extracts and serum containing antibody to Jo-1. Further studies by Matthews and Bernstein showed that sera containing antibody to Jo-1 could block the charging of histidine to its tRNA. They therefore postulated that Jo- 1 could be a histidyl-tRNA synthetase. ${ }^{30}$ This was confirmed by Yang et al, who purified histidyl-tRNA synthetase from rat liver and showed it to be identical to the Jo- 1 antigen. ${ }^{31}$

Since these studies, other tRNA-related autoantibodies have been detected in a small number of sera from patients with myositis. An autoantibody originally called PL-7 and directed against threonyl-tRNA ${ }^{32}$ was found in sera of five patients, four of whom had myositis. A similar autoantibody, which precipitated a ribonucleoprotein complex containing threonyltRNA and an unknown small RNA molecule, 
was reported in the sera of one paticnt with PM, ${ }^{33}$ and yet a third antibody, directed against both alanyl-tRNA synthetase and deproteinized tRNA, has been recently described. ${ }^{34}$

As with the previously described autoantibodies, no evidence directly linking these antibodies to the pathogenesis of muscle disease has been presented. Rather, the antibodies may serve as a clue to the etiology of PM. Identification of Jo- 1 and other tRNA-synthetase related antibodies has furthered speculation that PM is initiated by a viral infection. This association is based on two related facts. First, some of the RNA viruses of the enterovirus group have been shown to mimic small tRNAs in their ability to be charged with specific amino acids. ${ }^{35,36}$ Secondly, at least some cases of PM have been thought to have a viral etiology, and enteroviruses have been implicated in a range of muscle disorders. Coxsackieviruses, in particular, are known to produce both acute (Bornholm disease) as well as chronic (myocarditis) muscle disease.

On the basis of these data, Matthews and Bernstein have hypothesized that antibodies to
tRNA synthetase seen in patients with PM may result from the binding of the charging enzyme complex to viral RNA, rendering the host enzyme immunogenic. ${ }^{30}$ Thus, once a chronic inflammatory muscle disease has been established, the antibodies that have developed to the patient's own charging enzymes may be the only evidence remaining of a prior viral infection.

It is not known if these or any of the other autoantibodies found in patients with PM play a role in perpetuating the muscle inflammation or are merely epiphenomena. The variety of autoantibodies found in PM and DM serve to emphasize the heterogeneity of these syndromes. In the case of antibody to Jo- $I$, it is likely that its presence reflects the occurrence of a prior viral infection that may have acted to initiate the immunopathologic process observed in patients with PM, and thus may serve as a way of defining a particular clinical subset. Study of this more homogeneous group of patients may then lead to further understanding of both the etiology and pathogenesis of the inflammatory muscle diseases.

\section{REFERENCES}

1. Stern GM, Rose AL, Jacobs K: Circulating antibodies in polymyositis. J Neurol Sci 5:181-183, 1967

2. Caspary EA, Gubbay SS, Stern GM: Circulating antibodies in polymyostitis and other muscle-wasting disorders. Lancet 2:941, 1964

3. Wada K, Ueno S, Hazama T, et al: Radioimmunoassay for antibodies to human skeletal muscle myosin in serum from patients with polymositis. Clin Exp Immunol 52:297304, 1983

4. Nishikai M, Homma M: Anti-myoglobin antibody in polymyositis. Lancet 2:1205 1206, 1972

5. Nishikai M, Homma M: Circulating autoantibody against human myoglobin in polymositis. JAMA 237:18421844. 1977

6. Mimori T, Akizuki M, Yamagata $\mathrm{H}$, et al: Characterization of a high molecular weight acidic nuclear protein recognized by autoantibodies in sera from patients with polymyositis-scleroderma overlap. J Clin Invest 68:611-620, 1981

7. Mimori T, Hardin JA, Steitz JA: Characterization of the DNA-binding autoantigen Ku. Arthritis Rheum 28:S74, 1985 (suppl)

8. Wasicek C, Reichlin M, Montes M, et al: Polymyositis and interstitial lung disease in a patient with anti-Jo- 1 prototype. Am J Med 76:538-544, 1984

9. Targoff IN, Reichlin M; Unmasking of cytoplasmic fluorescence of anti-Jo- 1 by purification of antibody. Arthritis Rheum 28:S74, 1985 (suppl)

10. Nishikai M, Reichlin M: Purification and characterization of a nuclear nonhistone basic protein $(\mathrm{Mi}-1)$ which reacts with anti-immunoglobulin sera and the sera of patients with dermatomyositis. Mol Immunol 17:1129-1141, 1980

11. Targoff IN, Reichlin M: The association between Mi-2 antibodies and dermatomyositis. Arthritis Rheum 28:796-803, 1985

12. Wolff JF, Adelstein E, Sharp GC: Antinuclear antibody with distinct specificity for polymyositis. J Clin Invest 59:176-178, 1977

13. Reichlin M, Maddison PJ, Targoff IN, et al: Antibodies to a nuclear/nucleolar antigen in patients with polymyositis overlap syndromes. J Clin Immunol 4:40 44, 1984

14. Treadwell EL, Alspaugh MA, Wolfe JF, et al: Clinical relevance of PM-1 antibody and physiochemical characterization of PM-1 antigen. J Rheumatol 11:658-662, 1984

15. Targoff IN, Reichlin M: Nucleolar localization of the PM-Scl antigen. Arthritis Rheum 28:226-230, 1985

16. Lerner MR, Steitz JA: Antibodies to small nuclear RNAs complexed with proteins are produced by patients with systemic lupus crythematosus. Proc Natl Acad Sci USA $76: 5495-5499,1979$

17. Nakamura M, Mimori T, Hardin J: Anti-Ku antibodies in American patients with SLE: Detection with ELISA, immunoblotting, and immunodiffusion assays. Arthritis Rheum 28:S96, 1985

18. Arnett FC, Hirsch TJ, Bias WB, et al: The Jo-1 antibody system in myositis: Relationships to clinical features and HLA. J Rheumatol 8:925-930, 1981

19. Yang VW, Lerner MR, Steitz JA, et al: A smaller nuclear ribonucleoprotein is required for splicing of adenovi- 
ral early RNA sequence. Proc Natl Acad Sci USA 78:13711375,1981

20. Mimori $T$, Hinterberger $M$, Pettersson $I$, et al: Autoantibodies to the U2 small nuclear ribonucleoprotein in a patient with scleroderma-polymyositis overlap syndrome. J Biol Chem 259:560-565, 1984

21. Nishikai M, Reichlin M: Heterogeneity of precipitating antibodies in polymyositis and dermatomyositis: Characterization of the Jo-1 antibody system. Arthritis Rheum 23:881-888, 1980

22. Yoshida S, Akizuki M, Mimori T, et al: The precipitating antibody to an acidic nuclear protein antigen, the Jo-1, in connective tissue diseases. Arthritis Rheum 26:604-611, 1983

23. Bernstein RM, Morgan SH, Chapman J, et al: AntiJo-1 antibody: A marker for myositis with interstitial lung disease. Br Med J 289:151-152, 1984

24. Targoff IN, Raghu G, Reichlin M: Antibodies to Mi-1 in SLE: Relationship to other precipitins and reaction with bovine immunoglobulin. Clin Exp Immunol 53:76-82, 1983

25. Reichlin M, Arnett FC: Multiplicity of antibodies in myositis sera. Arthritis Rheum 27:1150-1156, 1984

26. Bohan A, Peter JB, Bowman RL, et al: A computerassisted analysis of 153 patients with polymyositis and dermatomyositis. Medicine 56:255-286, 1977

27. Reichlin M, Mattioli M: Description of a serological reaction characteristic of polymyositis. Clin Immunol Immunopathol 5:12-20, 1976
28. I erner MR, Boyle JA, Mount SM, et al: Are snR NP's involved in splicing? Nature (London) 283:220-224, 1980

29. Hochberg MC, Feldman D, Stevens MB, et al: Antibody to Jo-1 in polymyositis/dermatomyositis: Association with interstitial pulmonary disease. J Rheumatol 11:663665,1984

30. Matthews MB, Bernstein RM: Myositis autoantibody inhibits histidyl-tRNA synthetase: A model for autoimmunity. Nature 304:177-179, 1983

31. Yang DCH, Dang CV, Arnett FC: Rat liver histidyltRNA synthetase. Purification and inhibition by the myositis-specific anti-Jo-1 autoantibody. Biochem Biophys Res Comm 120:15-21, 1984

32. Matthews MB, Reichlin M, Hughes GRV, et al: Anti-threonyl-tRNA synthetase, a second myositis-related autoantibody. J Exp Med 160:420-434, 1984

33. Okada $N$, Mukai $R$, Harada F, et al: Isolation of a novel antibody, which precipitates ribonucleoprotein complex containing threonine tRNA from a patient with polymyositis. Eur J Biochem 139:425-429, 1984

34. Matthews MB, Bernstein RM, Bunn CC: Myositis sera recognize alanyl-tRNA synthetase and transfer RNA independently: Implications for autoimmunity. Arthitis Rheum 28:S32, 1985

35. Salomon R, Littauer UZ: Enzymatic acylation of histidine to mengovirus RNA. Nature 249:32-34, 1974

36. Lindley IJD, Stebbing N: Aminoacylation of encephalomyocarditis virus RNA. J Gen Virol 34:177-182, 1977 